\title{
PROBABILISTIC DESIGN OF COMPOSITE WHEEL SPANNER
}

\author{
Emmanuel SIMOLOWO1, * Michael MOSAKU1 \\ ${ }^{1}$ University of Ibadan, Faculty of Technology, Department of Mechanical Engineering, Nigeria
}

\author{
Received (17.03.2017); Revised (15.06.2017); Accepted (19.06.2017)
}

\begin{abstract}
Probabilistic design offers tools for making reliable decisions with the consideration of uncertainty associated with design parameters and simulation models. This project discusses probabilistic design and its application into design of a composite wheel spanner for Toyota Camry cars with five (5) lug nuts. The project work is aimed at taking advantage of probabilistic design system approach over deterministic (traditional) approach to create an optimised design model of an existing composite wheel spanner. This new approach is to implement changes on a controlled, verifiable basis and deals majorly with the operating stress and material strength. The pre-existing design was rigid, robust and was only designed for a Volkswagen Beetle car with four (4) lug nuts while the new design is compatible with the Toyota Camry and all cars with $60.1 \mathrm{~mm}$ Hub/Centre Bore, 14"-16" wheel size and $5 \times 114.3 \mathrm{~mm}$ bolt pattern. The design was drawn using SolidWorks design software and various design parameters were considered. The completed design was imported from SolidWorks to ANSYS software by converting the design into a Para solid which was then simulated by varying the speed of the shaft and the material in order to get the corresponding stress analysis. The rotational speed of the shaft was varied with different gear materials on ANSYS probabilistic design system software. The result shows that the lowest amount of stress was experienced when 7079 Aluminum Alloy $(\rho=$ $\left.2700 \mathrm{~kg} / \mathrm{m}^{3}\right)$ was tested at $100 \mathrm{rpm}$ but Magnesium Alloy $\left(\rho=1700 \mathrm{~kg} / \mathrm{m}^{3}\right)$ at $100 \mathrm{rpm}$ gave a higher minimum operating stress value. In this project, a 5-nut composite wheel spanner was successfully designed using probabilistic design approach. The pre-existing composite spanner was improved upon using SolidWorks and ANSYS software to design and analyse respectively. The new design is very flexible, adjustable and easy to carry. It can be adopted by car manufacturing companies.
\end{abstract}

Key words: Operating Stress, Rotational Speed, Composite-spanner, Magnesium Alloy, 7079 Aluminum Alloy,

\section{INTRODUCTION}

\subsection{Research Background}

Engineering designs rely on complex computer codes for more accurate, faster and better performance analyses [12]. Deterministic design employs the idea of either: (a) running these codes with input variables at their worst case values, or (b) running this code with input variables at their nominal values and applying a safety factor to the final result of the output variable. In the generic sense of modeling a typical response like stress, the result of using either of these methods is unknown. Assuming the input distributions are correct, applying worst case scenarios is too conservative. Applying safety factors to a nominal solution can result in either too much or too little conservatism with no method to compute risk or probability of occurrence.

Probabilistic engineering design relies on statistical distributions applied to the input variables to assess reliability, or probability of failure, in the output variable by specifying a design point. Any response value passing beyond this design point (also referred to as the most probable point, or MPP) is considered in the failure region. This method also allows for reverse calculations such that a specific probability of failure can be specified for the response. The MPP is then determined by calculating the response value that yields the specified probability of failure. This concept of designing to reliability instead of designing to nominal is clearly a superior method for engineering design. By choosing a desired reliability from a distribution on the response, a probabilistic risk assessment is built into the design process. [3] The foundation of probabilistic design involves basing design criteria on reliability targets instead of deterministic criteria. Design parameters such as applied loads, material strength, and operational parameters are researched and/or measured, then statistically defined. A probabilistic analysis model is developed for the entire system and solutions performed to yield failure probabilities [4].

\subsection{Introduction to Probabilistic and Deterministic Design}

Probability has been about interpreting the past and determining the future. Sometimes what we know in the past is no longer applicable in the future. We do not know for sure how good our sample is due to our uncertainty as humans, therefore we must try to generate sample data which indicates future behaviour in which we have very high confidence in. [5]. Probabilistic Design deals with the effects of random variability upon the performance of an engineering system during the design phase and these effects are related to quality and reliability. It offers tools for making reliable decisions with the consideration of uncertainty associated with design parameters and simulation models. One important task of a probabilistic

\footnotetext{
*Correspondence Author's Address: University of Ibadan, Faculty of Technology, Department of Mechanical Engineering, Nigeria, esimmar@yahoo.com; oe.simolowo@mail.ui.edu.ng
} 
design is uncertainty analysis; through which we understand how much the impact of the uncertainty associated with the system input is on the system output by identifying the probabilistic characteristics of system output. We then perform synthesis (optimization) under uncertainty to achieve the design objective by managing and mitigating the effects of uncertainty on system output (system performance). [6]

Probabilistic design methods, unlike deterministic methods, provide a means to quantify the risk of a design and to quantify the sensitivities of design variables. It allows engineers to quantify the reliability of the designed structure, as opposed to deterministic design which only determines whether the structure is safe or not. The clear difference between probabilistic design and deterministic design approach is that probabilistic design takes into account the uncertainties involved in the behaviour of the structures or machine under consideration [7]. The optimization stage of the engineering design process is a systematic process using design constraints and criteria to allow the designer to locate the optimal solution. Optimization achieves the "best" design relative to a set of prioritized criteria or constraints. These include maximizing factors such as productivity, strength, reliability, longevity, efficiency, and utilization. [8]. Engineers often identify appropriate design solutions and then decide which one best meets the need of the client. This decision-making process is known as optimization.

\subsection{Robust Design}

Robustness is the property of being strong and healthy in constitution. When it is transposed into a system, it refers to the ability of tolerating perturbations that might affect the system's functional body. In the same line Robustness can be defined as "the ability of a system to resist change without adapting its initial stable configuration" [9]. It has been discussed that robustness has two dimensions: resistance and avoidance. [10]. Robust design has been shown to be very effective in improving product or process design in manufacturing. In practice, most robust design applications have been limited to small systems with traditional statistical experimental design and analysis methods [11]. Robust Design is a methodology that addresses product quality issues early in the design cycle. The goal of Robust Design is to deliver customer expectations at affordable cost regardless of customer usage, degradation over product life and variation in manufacturing, suppliers, distribution, delivery and installation. [12].

The aim of this research work is to come up with an optimized and robust design of a composite wheel spanner which can tighten and loosen a 5-nut wheeled car using probabilistic approach method. The specific objectives of this project are: (i) To modify the existing design of a composite wheel spanner (ii) To vary design parameters and observe the effects by using SolidWorks for 3D software and ANSYS Probabilistic Design System (PDS) for modeling and simulating respectively. The project work will focus on the design modification and performance analysis of an existing composite spanner.

\section{PROBABILISTIC DESIGN CONCEPT}

The major advantage of designing with a probabilistic approach is the possibility to quantify the reliability of the structure. Instead of using characteristic values which correspond to upper or lower boundary values, a probabilistic approach allows engineers to quantify the reliability of the design. In most cases, the probabilistic approach of designing a structure gives results that are closer to reality and thus less conservative than a deterministic approach. This is of interest in design since it would allow us to design structures differently and save on materials and on money, as well as assessing the reliability of an existing structure and determining how far it is from failure. Moreover, it is a useful tool for assessing the reliability of existing structures since parameters can be adapted with respect to target reliability or importance of the building. Some basic concepts related to probability and statistics are: (i) probability density, with the mean value and standard deviation (ii) distribution function, with median value (iii) normal distribution, widely used for engineering and science applications in the context of structural design in engineering, it is of interest to quantify the safety and reliability of a structure, especially for existing structures.

\subsection{Quantifying the Reliability of a Structure}

Estimating the probability of failure is a good approach of quantifying the reliability of a structure. Probability of failure is a reliable indicator of structural safety and a useful tool from an engineering point of view. The basic principles of statistics and probability can be applied to a probabilistic analysis of structural safety and allow to mathematically express this concept of reliability. Two values need to be considered: (i) limit function $\mathrm{G}$ : $\mathrm{G}=R$ $S$ (where, $\mathrm{R}$ is resistance and $\mathrm{S}$ is solicitation). (ii) Reliability index $\mathrm{b}$, from which the failure probability $\left(P_{f}\right)$ can be directly determined

The failure probability of a structure is defined analytically as follows:

$P_{f}=\int_{-\infty}^{\infty} f_{S}(x) \cdot \operatorname{Fr}(x) d x$

Cumulative distribution function, $F_{r}$

$\operatorname{Fr}(x)=P(R<x)=\int_{-\infty}^{\infty} f r(x) d x$

Probability density function, $f_{S}$

$P[a<S<b]=\int_{a}^{b} f_{S}(x) d x$

In the SIA Standards for new constructions, $\beta$ is fixed at 4.7 , corresponding to a failure probability of $10^{-6}$. The design value defined through a probabilistic approach is defined as:

\section{Solicitation}

$\mathrm{S}^{*}=\mathrm{S}_{\mathrm{m}} \cdot\left(1+\beta . \alpha_{\mathrm{s} .} v_{\mathrm{s}}\right)$

$\mathrm{S}_{\mathrm{m}}=$ mean value, $\alpha=\frac{\sigma s}{\sigma G}=$ influence value and

$v_{s}=\frac{\sigma s}{S m}$ is variation coefficient. 


\section{Resistance}

$\mathrm{R}^{*}=\mathrm{R}_{\mathrm{m}} \cdot\left(1-\beta \cdot \alpha_{\mathrm{R}}, v_{\mathrm{R}}\right)$

$\mathrm{R}_{\mathrm{m}}=$ mean value, $\alpha=\frac{\sigma R}{\sigma G}=$ influence value and $v_{R}=\frac{\sigma R}{R m}=$ variation coefficient.

\subsection{Probabilistic Analysis}

In all stages of engineering design, and especially in conceptual stages, most available information suffers from uncertainty and it is important to bring this into the design process and through modeling and simulation tools. This is because important information about the design otherwise is omitted. For example, following information can be extracted if the uncertainty is taken into account: (i) The probability of meeting a set of requirements and achieve a technically feasible (ii) design with a particular concept, the probability of success (iii) How much it will be necessary to relax the requirements in order to have a sufficiently (iv) high probability of success (v) the effect on the probability of success if the concept is modified, for example by infusing new technologies.

The information above cannot be achieved using a deterministic approach (where uncertainty is not handled), but is necessary in order to make good decisions based on the simulation. This reasoning has led to an increased interest in the probabilistic design methodology where uncertainty is handled and given specific metrics throughout the design process. Well-defined methods have been developed for probabilistic analysis and have been evaluated in several projects showing the significance of this methodology. A typical approach to perform probabilistic analysis is to connect a Monte Carlo simulation to the analysis code which simulates the parameter uncertainty according to a probability density function (PDF). The Monte Carlo simulation is run for a large number of iterations in order to properly simulate the variability and generates input to the actual analysis code. As a result of the varying input to the analysis code, the responses will also vary, enabling a probabilistic analysis of the responses. Probabilistic analysis could also be related to stochastic analysis where also the uncertainty changes over time. [13] Probabilistic analysis requires that the random variables be statistically characterized. Statistical design databases, in general, do not exist. In order to conduct a probabilistic design exercise one must characterize many parameters, including the following: (i) Incoming material mechanical properties. (ii) External loads anticipated during the life of the article (iii) Manufacturing processes and their effect on material strength. (iv) Environmental effect on strength. (v) Environmental history during operational usage. (vi) Flaw locations, severity, probability of occurrence and effect on strength.

The basic probabilistic design concept looks into the probability distributions of both material strength and operating stress because failure is a local phenomenon, division of a component into nodes can be done to represent all the locations at which failure is possible to occur. In general, the distributions are assumed to be identical at all the nodes. Step (vii) assumes that material strengths at the nodes are independent from each other. In step (viii), if the calculated probability of failure does not agree with the pre-defined and acceptable level, sensitivity analysis resulting from changes in distribution(s) will provide invaluable information on needed changes in the design.

\section{PROBABILISTIC DESIGN OF COMPOSITE SPANNER}

\subsection{Description of Modified Design}

The new design of the composite spanner is an improvement over the existing one in the following aspects: (i) it has an adjustable stand so that it can be used with wheels of different heights (ii) It has the flexibility to suit various vehicles so as to loosen or tighten nuts (iii) It is designed with lighter materials to enable easy lifting to reduce the robustness of the previous design (iv) It is easy to assemble and disassemble for easy compatibility (v) There is improvement from 4-nuts to a 5-nut remover.

The newly designed composite spanner is aimed at reducing timeliness, improving robustness and also at increasing the flexibility of the composite spanner. The various parts of the newly developed are shown in figures $1-9$

The handle of the composite spanner helps transfer the force to produce torque needed to drive the gears without damaging the nuts. It's a detachable part which is connected to the pinion gear shat for use. The handle has a rubber end for easy handling and a socket mouth so as to fit firmly in behind the gear shaft. The gear box is a hollow cylinder designed to house the shaft, the driver and driven gears. In the design of the gear box the center of the wheel and the center of the wheel nuts were taken into consideration.

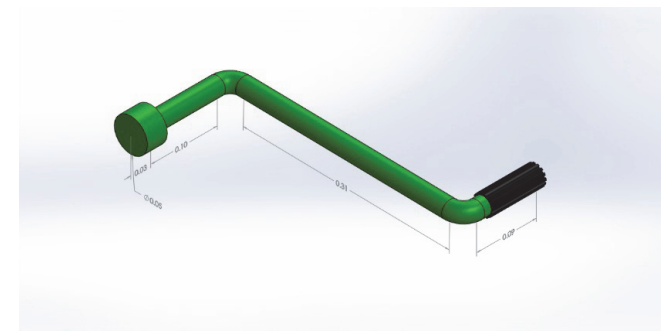

Fig.1. Handle

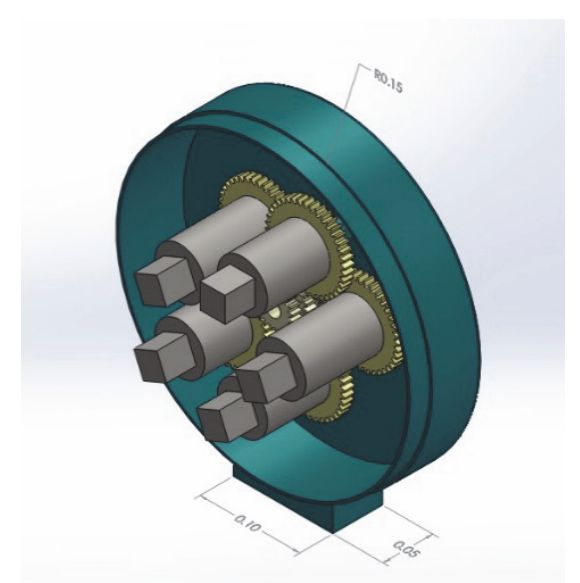

Fig.2. Gear Box 
The gear shaft is a cylindrical shaft found in the gear box that carries the three (3) pinion gears which rotates when the handle of the composite spanner is being turned thereby allows the transmission of the torque from the pinion to the spur gears.

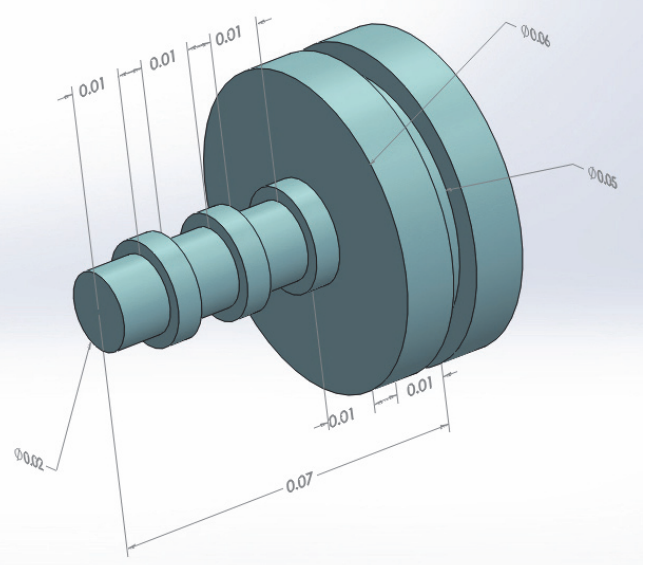

Fig.3. Gear Shaft

The adjustable stand is a long hollow cylindrical pipe that has holes where the stopper/pin passes through after the gear box has been set at a desirable height. It holds the gear box in place.

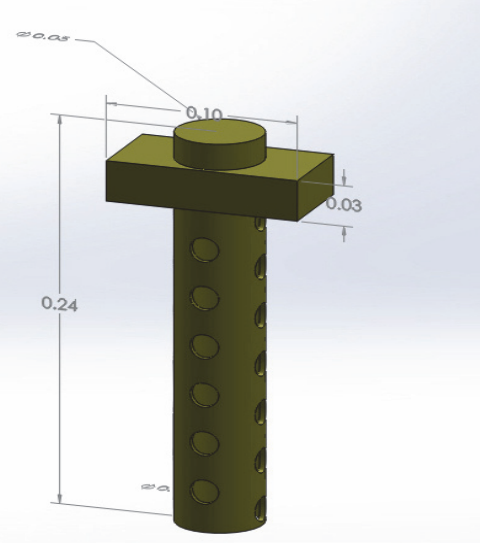

Fig.4. Adjustable Stand

The adjustable stand Pin helps hold the adjustable stand in place at a desirable height. It passes through the holes of the stand and rests on top of the base stand. The base stand is a rectangular box designed for stability. It carries the total weight of the composite spanner and holds the adjustable cylindrical pipe in place with the help of pin

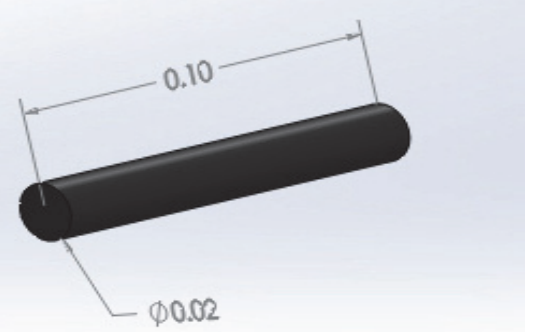

Fig.5. Adjustable Stand Pin

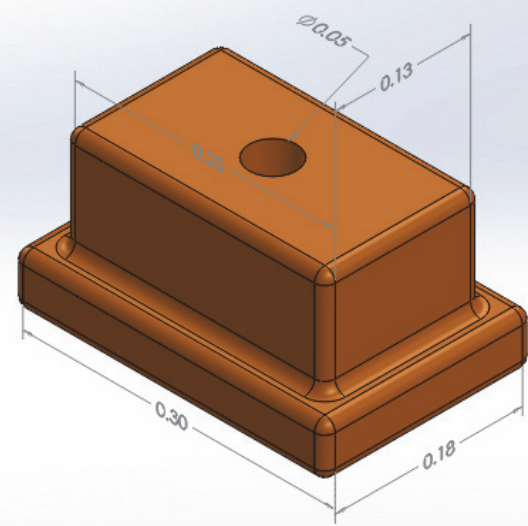

Fig.6. Base Stand

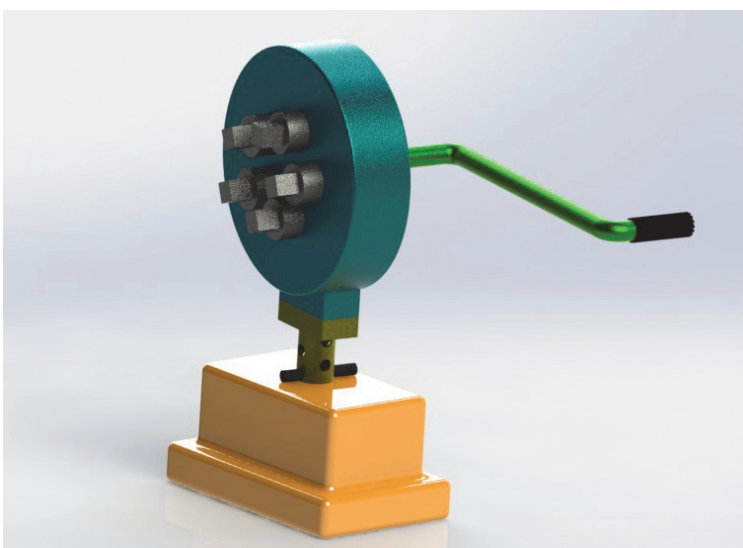

Fig. 7. Newly Designed Composite Spanner

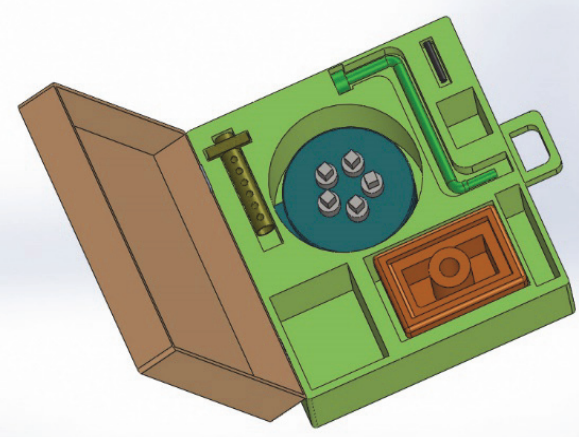

Fig.8. Composite Spanner Tool Box

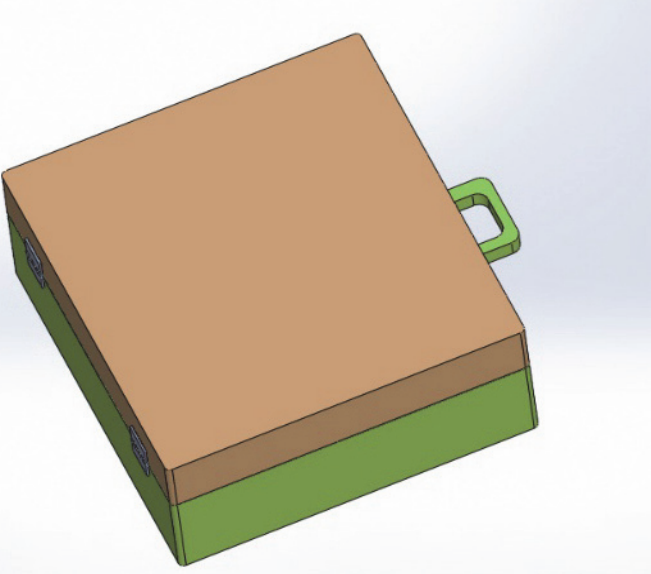

Fig.9. Closed Composite Spanner Tool Box 


\subsection{Advantages of the New Design}

1) The composite spanner improved on the number of nuts to be removed or tightened on the wheel hub.

2) Better gear ratio which makes the user exert less energy while using the new composite spanner compared to the old design

3) The new design can be raised or lowered to any convenient height with the help of the adjustable stand.

4) This new model can be used with all vehicles with $60.1 \mathrm{~mm}$ Bore Centre or Hub

5) It can be easily assembled and disassembled which makes it more compactible

\subsection{Design Parameters and Considerations}

The following considerations were taken into account when designing the gears: (i) The centre distance between the centre of the hub and the wheel nut (as shown in figure 10) (ii) Speed of the driving (iii) speed of the driven gear or velocity ratio (iv) power transmitted from the driving to the driven gear. Also the following requirements must be met in the design of a gear drive; (i) the teeth of the gear should be strong enough to resist failure during operation under both static and dynamic loading (ii) the drive gear should have the required material properties to perform its function (iii) the best material must be chosen for economic reasons (iv) the alignment of the gears and deflections of the shafts must be considered because they have effect on the performance of the gears $(v)$ the lubrication of the gears must be satisfactory.

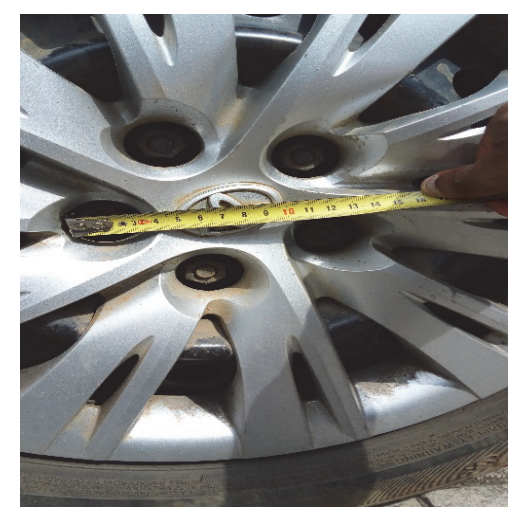

Fig.10. Taking Measurements of the Distance between the Centre Hub and Lug Nuts

\subsection{Design of the Pinion (Driver) and Driven Gears}

The composite spanner was to be designed for 120.2 PCD, so the center between the gears had to be $60.1 \mathrm{~mm}$. The average torque removal for one nut is $130 \mathrm{Nm}$. Spur gears were selected due to the function and the type of motion to be transfered. The velocity ratio in the gears is constant. The above factors where considered in selection and design calculations of the gear.

Centre Distance $=m .\left(\mathrm{N}_{1}+\mathrm{N}_{2}\right) / 2$

Number of teeth for Pinion is $\mathrm{N}_{1}$; Number of teeth for Spur is $\mathrm{N}_{2}$. To find Module form Centre Distance eq. (6) is used given the center distance. The Pitch Diameter is given by eq. (7). Whereas, the circular pitch is given by eq. (8). The diametrical pitch, gear ratio, outside diameters for pinion and gear, root diameters for pinion and gear, base circle diameters for both gears, base pitch and contact ratio for both gears are given by eq. (9), (10), (11), (12), (13), (14) and (15) respectively.

$\mathrm{D}=\mathrm{mN}$,

$\mathrm{P}_{\mathrm{c}}=\mathrm{m} \pi$

$\mathrm{P}_{\mathrm{d}}=\mathrm{N} / \mathrm{D}$

$\mathrm{G}=\mathrm{N}_{2} / \mathrm{N}_{1}$

$\mathrm{D}_{\mathrm{o}}=\mathrm{m}(\mathrm{N}+2)$

$\mathrm{D}_{\mathrm{R}}=\mathrm{D}-2.5 \mathrm{~m}$

$\mathrm{D}_{\mathrm{B}}=\mathrm{D} \cos \alpha$

$\mathrm{P}_{\mathrm{B}}=\mathrm{m} \pi \cos \alpha$

$\mathrm{C}_{\mathrm{R}}=\left(\sqrt{\mathrm{R}_{\mathrm{O} 1}}{ }^{2}-\mathrm{R}_{\mathrm{b} 1}{ }^{2}+\sqrt{\mathrm{R}_{\mathrm{O} 2}}{ }^{2}-\mathrm{R}_{\mathrm{b} 2}{ }^{2}\right.$

$-\mathrm{C} \sin \alpha) / \mathrm{m} \pi \cos \alpha ; \quad\left(1<\mathrm{C}_{\mathrm{R}}<2\right)$

The torque spanner provides the required torque for the bolts without over tightening or under tightening of the lug nuts. The manufacturers catalogue (Toyota Camry) for tightening M12 nut is given as $350 \mathrm{Nm}$. Therefore, to determine the required force that should be applied to the handle of the composite wheel spanner; we use the relation between force and torque in eq. (16).

Force $=\frac{\text { Torque }}{\text { Radius }}$

Therefore, a force of $\mathbf{1 5 8 N}$ is to be applied to a lever length of $0.55 \mathrm{~m}$ to produce the desired effect, which is to tighten the bolt to the required torque without failure of the bolts. the bolts. The table below shows the torque that should be applied to different sizes of bolts and the length of the lever that should be used to produce the given torque.

\subsection{Shaft Design}

The shafts that will be used in transmitting power and rotational motion in the composite wheel spanner is a solid shaft $\{$ that is, not hollow\}. To determine the diameter of the shaft, the eq. (17) is used;

$$
D=\text { Diameter of shaft }=\sqrt[3]{\frac{16 I}{\pi S_{S}}}
$$

Where, $\mathrm{T}=$ Torque; $\mathrm{S}_{\mathrm{S}}=$ Allowable shear stress is $55 \mathrm{MN} / \mathrm{m}^{2}$ for shafts without keyway and $40 \mathrm{MN} / \mathrm{m}^{2}$ for shafts with keyway. To calculate for angle of twist, eq. (18) is applied

$\theta=\frac{T L}{G J}$

Where $\mathrm{G}=$ Modulus of rigidity $=79.3 \mathrm{GPa}$ for Structural Steel. J, the polar moment on inertia of shaft cross section is given by eq. (19).

$J=\frac{\pi D^{4}}{32}$ 
Table 1. Torque values to be applied to a bolt

\begin{tabular}{|c|c|c|c|c|c|c|}
\hline $\begin{array}{c}\text { Square } \\
\text { drive size }\end{array}$ & $\begin{array}{c}\text { Torque } \\
\text { tool } \\
(\mathrm{Nm})\end{array}$ & $\begin{array}{c}\text { Hand tool } \\
\text { breaker / T- } \\
\text { handle (Nm } \\
\text { to ISO3315) }\end{array}$ & $\begin{array}{c}\text { Biggest } \\
\text { bolt/nut }\end{array}$ & $\begin{array}{c}\text { Socket size } \\
(\mathrm{mm})\end{array}$ & $\begin{array}{c}\text { Bolt/nut } \\
\text { torque } \\
(\mathrm{Nm})\end{array}$ & $\begin{array}{c}\text { Length of lever to } \\
\text { center of hand(s) for } \\
\text { lower torque limit }\end{array}$ \\
\hline $1 / 4 "$ & 25 & $62 / 55$ & $\mathrm{M} 8$ & 13 & 25 & $0.12 \mathrm{~m}$ (one hand) \\
\hline $3 / 8^{\prime \prime}$ & 110 & $202 / 180$ & $\mathrm{M} 10$ & 17 & 76 & $0.32 \mathrm{~m}$ (one hand) \\
\hline $1 / 2 "$ & 350 & $512 / 455$ & $\mathrm{M} 12$ & 19 & 87 & $0.55 \mathrm{~m}$ (one hand) \\
\hline $3 / 4 "$ & 1500 & $1412 / 1255$ & $\mathrm{M} 18$ & 27 & 294 & $0.88 \mathrm{~m}$ (two hands) \\
\hline $1 "$ & 4500 & $2515 / 2236$ & $\mathrm{M} 30$ & 46 & 1440 & $3.13 \mathrm{~m}$ (two hands) \\
\hline
\end{tabular}

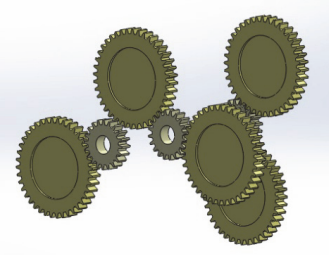

Fig.11. Exploded view of gear and shaft arrangement

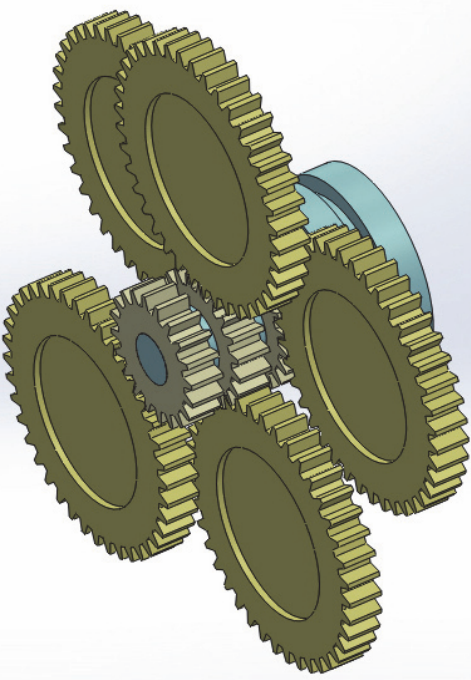

Fig.12. Gear arrangement

\section{RESULTS AND DISCUSSIONS}

Shown in figures $11-13$ are the components that were analysed using the ANSYS probabilistic design software. The composite spanner was designed with SolidWorks software and analysed using ANSYS Probabilistic Design Software to check the stress pattern. When the carbon steel material was used, the maximum stress recorded at $300 \mathrm{rpm}$ was $4.894 \times 10^{8} \mathrm{~Pa}$ and the minimum stress recorded at $100 \mathrm{rpm}$ was $187.83 \mathrm{~Pa}$. From figures $14-18$, that Maximus Stress is experienced when materials are put under high speed while the lowest amount of stress was experienced when 7079 Alloy was tested at $100 \mathrm{rpm}$. There is an obvious pattern which shows that the stress on the pinion gear and spur gears is a function of the rotational speed applied.

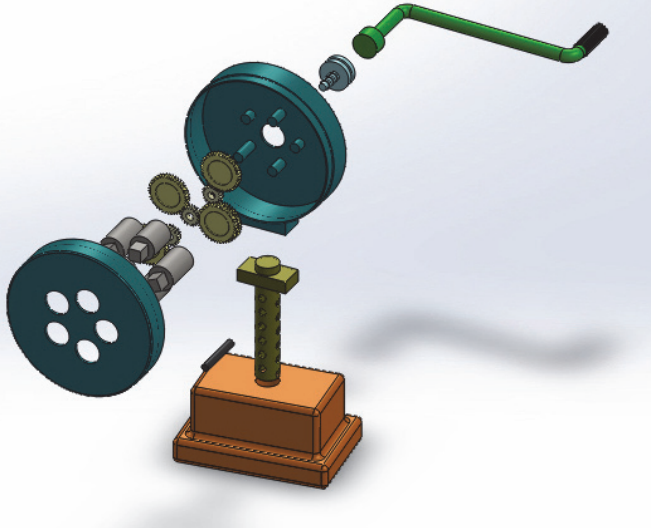

Fig. 13. Exploded view of the composite spanner

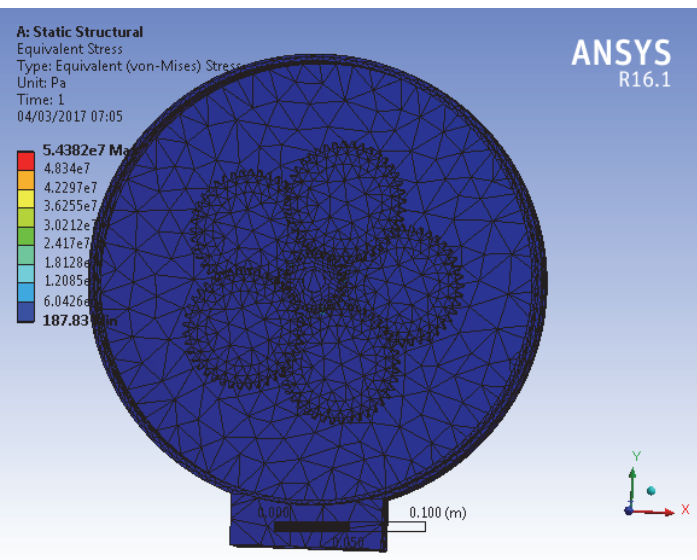

Fig.14. Stress analysis of the gears using carbon steel $\left(\rho=7858 \mathrm{~kg} / \mathrm{m}^{3}\right)$

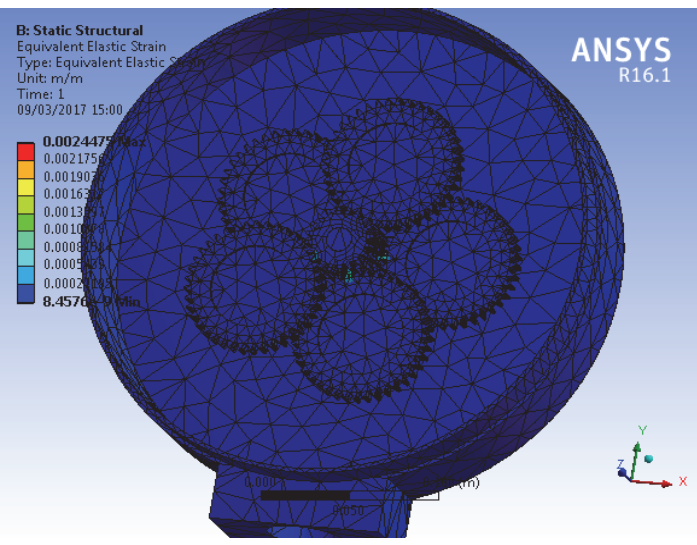

Fig. 15. Stress analysis of the gears using plain steel carbon $\left(\rho=7800 \mathrm{~kg} / \mathrm{m}^{3}\right)$ 


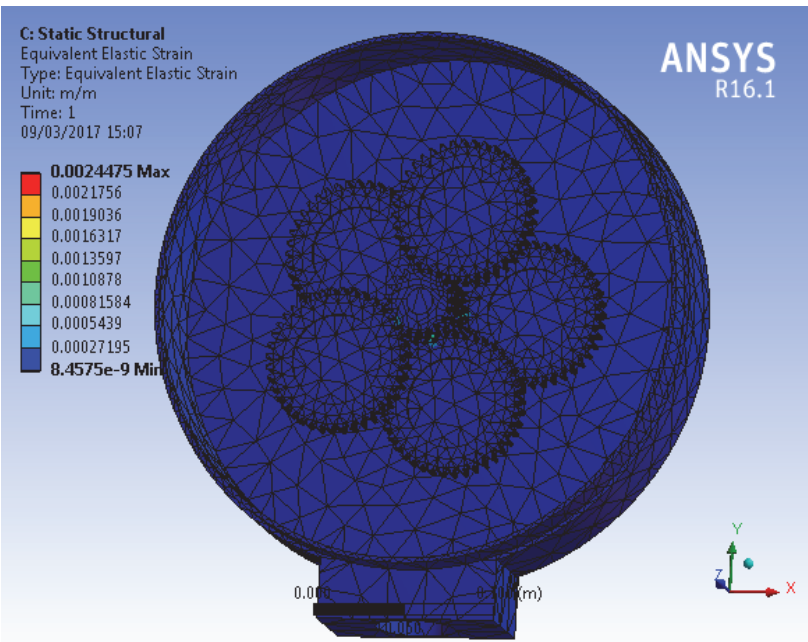

Fig.16. Stress analysis of the gears using cast alloy steel $\left(\rho=7300 \mathrm{~kg} / \mathrm{m}^{3}\right)$

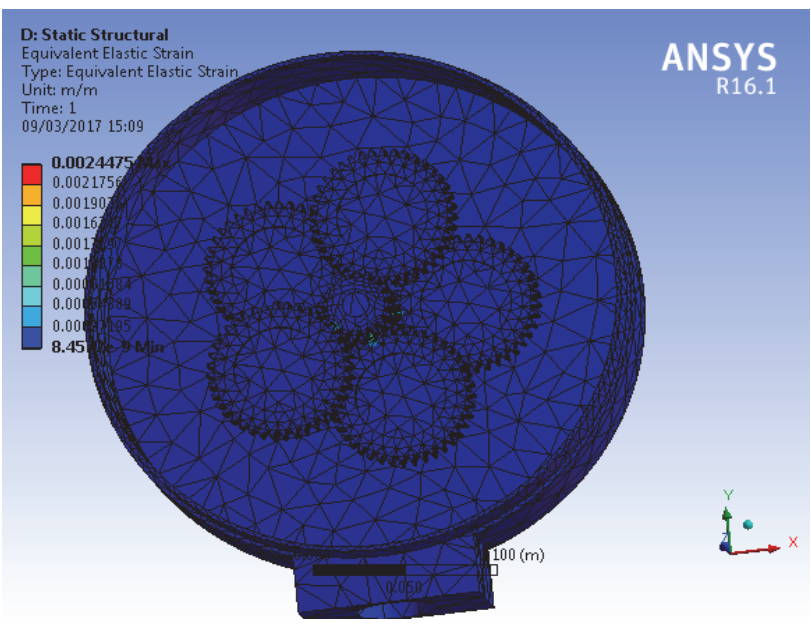

Fig.17. Stress analysis of the gears using magnesium alloy $\left(\rho=1700 \mathrm{~kg} / \mathrm{m}^{3}\right)$

Table 2. Stress analysis varying gear materials and speed

\begin{tabular}{|c|c|c|c|}
\hline Mat & RPM & $\begin{array}{l}\text { Min } \\
{[\mathrm{Pa}]}\end{array}$ & $\operatorname{Max}[\mathrm{Pa}]$ \\
\hline \multirow{3}{*}{$\begin{array}{c}\text { Carbon Steel } \\
\text { Sheet } \\
\left(\rho=7858 \mathrm{~kg} / \mathrm{m}^{3}\right)\end{array}$} & 100 & 187.83 & $5.438 \times 10^{7}$ \\
\hline & 200 & 751.25 & $2.175 \times 10^{8}$ \\
\hline & 300 & 1690.50 & $4.894 \times 10^{8}$ \\
\hline \multirow{3}{*}{$\begin{array}{c}\text { Plain Carbon } \\
\text { Steel } \\
\left(\rho=7800 \mathrm{~kg} / \mathrm{m}^{3}\right)\end{array}$} & 100 & 187.93 & $3.438 \times 10^{7}$ \\
\hline & 200 & 751.8 & $2.175 \times 10^{8}$ \\
\hline & 300 & 1691.5 & $4.895 \times 10^{8}$ \\
\hline \multirow{3}{*}{$\begin{array}{l}\text { Cast Alloy Steel } \\
\left(\rho=7300 \mathrm{~kg} / \mathrm{m}^{3}\right)\end{array}$} & 100 & 187.95 & $5.438 \times 10^{7}$ \\
\hline & 200 & 751.77 & $2.175 \times 10^{8}$ \\
\hline & 300 & 169 & $4.895 \times 10^{8}$ \\
\hline \multirow{3}{*}{$\begin{array}{l}\text { Magnesium Alloy } \\
\left(\rho=1700 \mathrm{~kg} / \mathrm{m}^{3}\right)\end{array}$} & 100 & 187.96 & $5.438 \times 10^{7}$ \\
\hline & 200 & 751.76 & $2.175 \times 10^{8}$ \\
\hline & 300 & 1691.40 & $4.894 \times 10^{8}$ \\
\hline \multirow{3}{*}{$\begin{array}{c}7079 \text { Alloy } \\
\left(\rho=2700 \mathrm{~kg} / \mathrm{m}^{3}\right)\end{array}$} & 100 & 5.87 & $1.489 \times 10^{7}$ \\
\hline & 200 & 23.50 & $5.959 \times 10^{7}$ \\
\hline & 300 & 52.84 & $1.341 \times 10^{8}$ \\
\hline
\end{tabular}

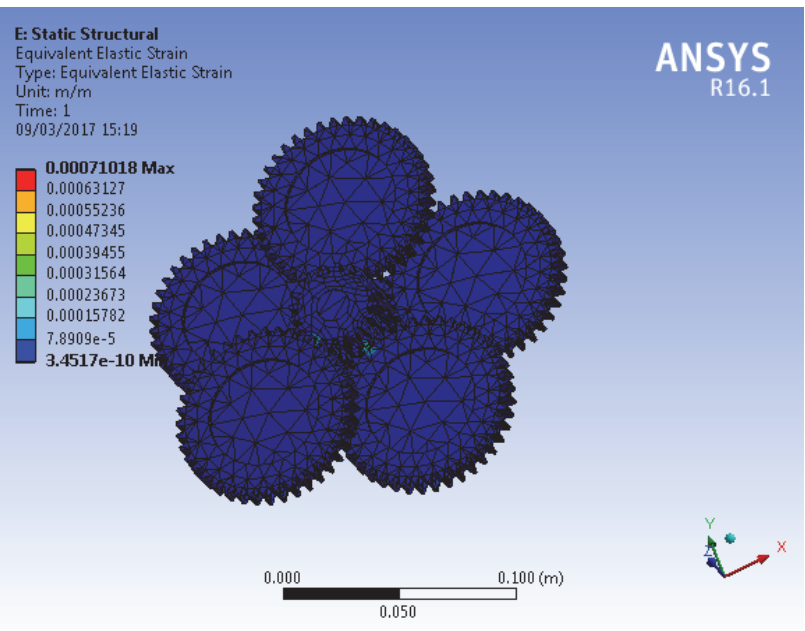

Fig. 18. Stress analysis on the gears using 7079 alloy $\left(\rho=2700 \mathrm{~kg} / \mathrm{m}^{3}\right)$

\section{CONCLUSION}

In engineering, the aim is usually to reduce time spent on doing work and to make work done as easy as possible. With the design of the composite wheel spanner, this was achieved. The new composite wheel spanner which has been designed with SolidWorks and analysed with ANSYS Probabilistic Design System software to loosen and tighten five (5) lug nuts at the same time in order to reduce the time spent in carrying out this operation has been achieved. With this design, each vehicle has its own compact composite wheel spanner which can be easily assembled and disassembled back into its box.

The new design can work for various models of salon cars which has $60.1 \mathrm{~mm}$ hub/center bore especially the Toyota brands such as Avalon, Camry, Solara, Celica, Corolla XRS, Cressida, Highlander, Previa, Sienna amongst others which is commonly used in this part of the world The aim of the project is to reduce the time spent on loosening/tightening the five (5) lug nuts of a wheel and to reduce the amount of force exerted to loosen/tighten the bolts/nuts by changing the gear ratio. The composite wheel spanner is reliable and easy to use. During the design phase of the 5-nut composite wheel spanner, the problem encountered was how to arrange the gears, with a small pinion gear to drive five (5) spur gears in order to increase output torque all on one shaft in the gear box. This was resolved by thinking outside the box and offsetting the spur gears by introducing two extra pinion gears. With this design, the challenge was solved and the design of the composite wheel spanner was completed.

\section{REFERENCES}

[1] Simolowo, E., Gbadebo, A. (2012). Developing A Dynamic Load-Tracking Learning-Software for Winch Lift Design, Machine Design, Vol.4, No.1, pp. 15-20, ISSN 1821-1259.

[2] Simolowo, E., Olumide, T., (2012). Developing A Learning Algorithm For The Design Of A Petrol Engine Powered Air Compressor. Machine Design, Vol.5, No.1, pp. 31-36, ISSN 1821-1259. 
[3] Craney, A. (2003). Probabilistic Engineering Design. Reprinted from Reliability Review, the $R \& M$ Engineering Journal, Vol.23, No.2, June 2003.

[4] Aviation Research Washington, D.C. 20591 (1999). Probabilistic Design Methodology for Composite Aircraft Structures.

[5] William, J.H. (1999). Probabilistic Design Methodology for Composite Aircraft Structures.

[6] Du, X., Chen, W. (2000). Sequential Optimization and Reliability Assessment Method for Efficient Probabilistic Design.

[7] Vrijling, J.K., P.H.A.J.M. van Gelder, Voortman, H.G., (accessed 2017) Design Applications: State of the Art of Probabilistic Design Tools.

[8] Merrill, C., Custer, R., Daugherty, J., Westrick, M., \& Zeng, Y. (2007). Delivering core engineering concepts to secondary level students. American Society for Engineering Education Conference Paper.
[9] Wieland, A., Wallenburg, C.M. (2012). Dealing with supply chain risks: Linking risk management practices and strategies to performance. International Journal of Physical Distribution \& Logistics Management, Vol.42, No.10.

[10]Durach, C.F. et al. (2015). Antecedents and dimensions of supply chain robustness: a systematic literature review, International Journal of Physical Distribution \& Logistics Management, Vol.45, No. 1/2, pp. 118-137.

[11] Murphy, T.E., Kwok-Leung Tsui, Y.L., Allen, J.K., Chen, V., Mistree, F. (2004), Robust Design for Optimizing Product Platforms.

[12] Vlahinos, A., Kelly, K., Pesaran, A., Penney, T. (2002). Empowering Engineers to Generate SixSigma Quality Designs.

[13] Johansson, B.D.1, DeLaurentis, A., Mavris, D.N. (1999). Managing Design Data for Probabilistic Evaluation of Aircraft Concepts.

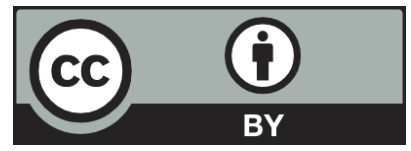

(C) 2017 Authors. Published by the University of Novi Sad, Faculty of Technical Sciences.

This article is an open access article distributed under the terms and conditions of the Creative Commons Attribution license 3.0 Serbia (http://creativecommons.org/licenses/by/3.0/rs/). 